\title{
Pulmonary hypertension and right ventricular function in the sickle cell populace
}

\author{
Opeyemi Oni ${ }^{1}$, Adewole Adebiyi ${ }^{2}$, and Akinyemi Aje ${ }^{2}$ \\ ${ }^{1}$ Bowen University College of Health Sciences \\ ${ }^{2}$ University College Hospital Ibadan
}

April 28, 2020

\begin{abstract}
Sickle cell anaemia(SCA) is a recognized cause of heart failure and pulmonary hypertension(PHT). However, the impact of PHT of right ventricular(RV) function has not been well elucidated. Objective To determine the impact of PHT on right ventricular function in patients with SCA. Methods Cases were adults with SCA with PHT. Controls were SCA patients without pulmonary hypertension. All patients were recruited in steady-state. Echocardiography was done for cases and controls. Measures of RV function used were RV fractional area change (RV FAC), peak tricuspid annular systolic velocity (S') and Tricuspid annular plane systolic excursion (TAPSE). Pulmonary hypertension was estimated from Tricuspid regurgitation jet velocities. Right atrial pressure was estimated using the ratio of the Trans tricuspid early diastolic velocity to the early tissue doppler diastolic velocity of the tricuspid annulus. Values $>35 \mathrm{mmHg}$ were said to have PHT. Results Out of 86 patients, there were 36 people with SCA that had tricuspid regurgitation- 11 with PHT, 25 without PHT. The mean values of RV systolic function- RV FAC (0.41SD0.1 vs 0.41SD0.1; $\mathrm{p}=0.999)$, S' (16.5SD5.1 vs 15.9SD4.3; $\mathrm{p}=0.116)$ and TAPSE (30.7SD5 vs 29.7SD4.3; $\mathrm{p}=0.389)$ were not significantly different between cases and controls respectively. Trans tricuspid E/A ratio (1.49SD0.4 vs 1.61SD0.4; p=0.381) was essentially the same between both groups while the early trans tricuspid deceleration time showed a trend towards being shorter in those with PHT (194.1SD35.1vs 223.3SD53.6; $\mathrm{p}=0.084$ ). Conclusion: The prevalence of PHT was $12.8 \%$ in SCA patients. There is no significant impact of PHT on RV function in SCA.
\end{abstract}

Opeyemi O. ONI 11Department of Medicine, Bowen University Teaching Hospital, Ogbomoso. Oyo state, Nigeria. This author takes responsibility for all aspects of the reliability and freedom from bias of the data presented and their discussed interpretation, MBBS, FWACP; Adewole A. ADEBIYI 22Department of Medicine, University College Hospital, Ibadan. Oyo state, Nigeria. This author takes responsibility for all aspects of the reliability and freedom from bias of the data presented and their discussed interpretation, MBBS, FWACP; Akinyemi AJE 33Department of Medicine, University College Hospital, Ibadan. Oyo state, Nigeria. This author takes responsibility for all aspects of the reliability and freedom from bias of the data presented and their discussed interpretation MBBS, FMCP

Corresponding Author: Oni Opeyemi Olalekan Department of Medicine, Bowen University Teaching Hospital, Ogbomoso. oniopeyemi64@gmail.com +234(0)8058435811

No grant support acknowledged.

No conflict of interest declared as there are no grant supports or shareholders' funding for this study.

\section{Hosted file}

Highlights of the study-Pulm htn SCA.docx available at https://authorea.com/users/309669/articles/ 440553-pulmonary-hypertension-and-right-ventricular-function-in-the-sickle-cell-populace

\section{Hosted file}


Pulm htn and right ventricular fxn.docx available at https://authorea.com/users/309669/articles/ 440553-pulmonary-hypertension-and-right-ventricular-function-in-the-sickle-cell-populace 